\title{
Lipid-based systems as a promising approach for enhancing the bioavailability of poorly water-soluble drugs
}

\author{
KATJA ČERPNJAK ${ }^{1}$ \\ ALENKA ZVONAR ${ }^{2}$ \\ MIRJANA GAŠPERLIN ${ }^{2 *}$ \\ FRANC VREČER ${ }^{1,2}$ \\ 1 Krka, d.d., Novo mesto, 8501 Novo mesto \\ Slovenia \\ ${ }^{2}$ Fakulteta za farmacijo, 1000 Ljubljana \\ Slovenia
}

\begin{abstract}
Low oral bioavailability as a consequence of low water solubility of drugs is a growing challenge to the development of new pharmaceutical products. One of the most popular approaches of oral bioavailability and solubility enhancement is the utilization of lipid-based drug delivery systems. Their use in product development is growing due to the versatility of pharmaceutical lipid excipients and drug formulations, and their compatibility with liquid, semi-solid, and solid dosage forms. Lipid formulations, such as self-emulsifying (SEDDS), self-microemulsifying SMEDDS) and self-nanoemulsifying drug delivery systems (SNEDDS) were explored in many studies as an efficient approach for improving the bioavailability and dissolution rate of poorly water-soluble drugs. One of the greatest advantages of incorporating poorly soluble drugs into such formulations is their spontaneous emulsification and formation of an emulsion, microemulsion or nanoemulsion in aqueous media. This review article focuses on the following topics. First, it presents a classification overview of lipid-based drug delivery systems and mechanisms involved in improving the solubility and bioavailability of poorly water-soluble drugs. Second, the article reviews components of lipid-based drug delivery systems for oral use with their characteristics. Third, it brings a detailed description of SEDDS, SMEDDS and SNEDDS, which are very often misused in literature, with special emphasis on the comparison between microemulsions and nanoemulsions.
\end{abstract}

Keywords: lipid-based drug delivery systems (LBDDS), self-emulsifying drug delivery systems (SEDDS), self-microemulsifying drug delivery systems (SMEDDS), self-nanoemulsifying drug delivery systems (SNEDDS), microemulsions, nanoemulsions

\footnotetext{
* Correspondence; e-mail: mirjana.gasperlin@ffa.uni-lj.si
} 
K. Čerpnjak et al.: Lipid-based systems as a promising approach for enhancing the bioavailability of poorly water-soluble drugs, Acta Pharm. 63 (2013) 427-445.

Most of the newly developed drugs are hydrophobic and therefore poorly water-soluble, which causes difficulties in selecting the proper delivery system to achieve sufficient bioavailability of such drugs. Poor water solubility and dissolution rate are restrictive factors with respect to their absorption rate and bioavailability. Undoubtedly, the majority of drugs marketed worldwide are administered orally. The efficacy of these drugs is dependent on their oral bioavailability, which, in turn, depends on several factors; the most important being drug solubility in an aqueous environment and drug permeability through lipophilic membranes (1-3). Orally administered drugs are completely absorbed only when they show good solubility in the gastric medium. According to the solubility factor (low/high) and permeability through biological membranes (low/ high), these drugs are commonly classified as Class 2 (low solubility, high permeability) or Class 4 (low solubility, low permeability) drugs according to the biopharmaceutical classification system (BCS), both of which identify solubility as a challenge. Due to the essential influence of solubility on drug bioavailability, numerous strategies have been developed to improve the solubility, and consequently absorption and bioavailability of poorly water-soluble drugs. Among the most promising approaches are lipid-based delivery systems (LBDDS) $(4,5)$, which have gained considerable research attention in the last 15 years after recognition that the oral bioavailability of poorly water-soluble drugs may be enhanced when they are co-administered with meals rich in fat, and after the commercial success of Sandimune $\mathrm{Neoral}^{\circledR}$ (Cyclosporine A), Fortovase ${ }^{\circledR}$ (Saquinavir) and Norvir ${ }^{\circledR}$ (Ritonavir) (4-7).

Some of the commercially available pharmaceutical products formulated as self-emulsifying delivery systems are presented in Table I.

Various types of LBDDS are known; from simple oil solutions or oily suspensions to coarse, multiple and dry emulsions, and more complex self-emulsifying, microemulsifying or nanoemulsifying drug delivery systems (SEDDS/SMEDDS/SNEDDS) (9). The

Table I. Examples of LBDDS on the market $(3,7,8)$

\begin{tabular}{llll}
\hline Product name & Drug & Dosage form & Company \\
\hline Sandimmune Neoral $^{\circledR}$ & cyclosporine A/I & soft gelatine capsule & Novartis \\
Gengraf $^{\circledR}$ & cyclosporine A/III & hard gelatine capsule & Abbott \\
Norvir $^{\circledR}$ & ritonavir & soft gelatine capsule & Abbott \\
Fortovase $^{\circledR}$ & saquinavir & soft gelatine capsule & Roche \\
Agenerase $^{\circledR}$ & amprenavir & soft gelatine capsule & GlaxoSmithKline \\
Lipirex $^{\circledR}$ & fenofibrate & hard gelatine capsule & Sanofi-Aventis \\
Convulex $^{\circledR}$ & valproic acid & soft gelatine capsule & Pharmacia \\
Rocaltrol $^{\circledR}$ & calcitriol & soft gelatine capsule & Roche \\
Targretin $^{\circledR}$ & bexarotene & soft gelatine capsule & Novartis \\
Vesanoid $^{\circledR}$ & tretinoine & soft gelatine capsule & Roche \\
Accutane $^{\circledR}$ & isotretionine & soft gelatine capsule & Roche \\
Kaletra $^{\circledR}$ & lopinavir and ritonavir & oral solution & Abbott \\
Aptivus $^{\circledR}$ & tipranavite & soft gelatine capsule & Boehringer Ingelheim \\
\hline
\end{tabular}


K. Čerpnjak et al.: Lipid-based systems as a promising approach for enhancing the bioavailability of poorly water-soluble drugs, Acta Pharm. 63 (2013) 427-445.

last three have a fairly similar composition, which comprises a mixture of oils, surfactants, and possibly co-solvents that has the ability to form fine oil-in-water $(O / W)$ emulsions, microemulsions or nanoemulsions upon mild agitation following dilution with an aqueous medium.

This review focuses on the presentation and differentiation of various lipid based drug delivery systems for oral application, and their mechanisms for improving the solubility and bioavailability of poorly water soluble drugs. Special attention will be paid to differentiation of SEDDS, SMEDDS and SNEDDS.

\section{Lipid-based drug delivery systems (LBDDS)}

There are increasing demands to develop suitable drug-carrier systems in order to control, localize, and improve drug delivery. LBDDS can reduce the inherent limitation of slow and incomplete dissolution of poorly soluble drugs and facilitate formation of solubilized structures after digestion in the gastrointestinal tract (GIT), from which absorption may occur (10).

A LBDDS is typically composed of lipids and surfactants, and may also contain a hydrophilic co-solvent. According to the lipid formulation classification system (LFCS) introduced by Pouton $(11,12)$, these systems are divided into four groups (I-IV), depending on their composition and the possible influence of dilution and digestion on their ability to prevent drug precipitation. This classification system enables differentiation among various systems hiding behind the term »lipid-based delivery systems « and also offers a better explanation and comparison of reported data (9-12). The composition, properties, advantages, and disadvantages of systems from each group of LFCS are presented in Table II.

Class I systems include simple oil solutions without surfactants, containing only mono-, di-, and/or tri-glycerides. Systems of Class II contain lipophilic surfactants in addition to the oil phase in order to increase the solubilization capacity of the systems for incorporated drugs, and to facilitate the stability of the emulsion formed upon dilution. These LBDDS are known as SEDDS. The addition of hydrophilic components (surfactants and/or co-solvents) to the oil phase creates SMEDDS, which belong to Class III systems. Representatives of the most hydrophilic group, Class IV, are systems that are only composed of hydrophilic surfactants and hydrophilic co-solvents, which form a colloidal micellar dispersion upon dilution with aqueous media (11).

\section{Strategies to enhance the bioavailability of orally administered poorly water-soluble drugs}

The effectiveness of LBDDS to improve the gastrointestinal absorption of poorly water-soluble drugs is well documented. It is suggested that improved absorption is predominantly due to their higher solubilization capacity, being a prerequisite for absorption from the GIT. The lipid droplets formed upon dispersion of self-emulsifying LBDDS may directly facilitate drug absorption, regardless of the bile salt-mediated mixed micelle transport system. Other mechanisms proposed include protection of the drug inside the lipid droplets from chemical and enzymatic degradation, localized in the aqueous environment, changes in gastrointestinal membrane permeability, and promo- 
K. Čerpnjak et al.: Lipid-based systems as a promising approach for enhancing the bioavailability of poorly water-soluble drugs, Acta Pharm. 63 (2013) 427-445.

Table II. Lipid formulation classification system by Pouton: structure, characteristics, advantages, and disadvantages of lipid-based systems $(11,12)$

\begin{tabular}{|c|c|c|c|c|c|}
\hline Classes & I & II & IIIa & IIIb & IV \\
\hline $\begin{array}{ll} & \text { Glycerides (mono-, } \\
\text { di-, tri-glycerides) }\end{array}$ & 100 & $40-80$ & $40-80$ & $<20$ & 0 \\
\hline $\begin{array}{ll}\text { : } & \text { Lipophilic surfac- } \\
\text { : } & \text { tants }(\text { HLB }<12)\end{array}$ & 0 & $20-60$ & $20-40$ & 0 & $0-20$ \\
\hline $\begin{array}{ll}\text { द्वे } & \text { Hydrophilic surfac- } \\
\text { ठิ } & \text { tants (HLB > 12) }\end{array}$ & 0 & 0 & 0 & $20-50$ & $20-80$ \\
\hline Co-solvents & 0 & 0 & $0-40$ & $20-50$ & $0-80$ \\
\hline Characteristic features & $\begin{array}{l}\text { Simple oil } \\
\text { solution }\end{array}$ & $\begin{array}{l}\text { Self-emulsi- } \\
\text { fying ability }\end{array}$ & $\begin{array}{l}\text { Self-emulsi- } \\
\text { fying ability }\end{array}$ & $\begin{array}{l}\text { Self-micro- } \\
\text { mulsifying } \\
\text { ability }\end{array}$ & $\begin{array}{l}\text { Spontaneous } \\
\text { formation } \\
\text { of micellar } \\
\text { dispersion }\end{array}$ \\
\hline Advantages & $\begin{array}{l}\text { GRAS (ge- } \\
\text { nerally rec- } \\
\text { ognized as } \\
\text { safe) status } \\
\text { Capsule } \\
\text { compatibility }\end{array}$ & $\begin{array}{l}\text { Unlikely to } \\
\text { lose solvent } \\
\text { capacity on } \\
\text { dispersion }\end{array}$ & $\begin{array}{l}\text { Formation } \\
\text { of clear / } \\
\text { opalescent } \\
\text { dispersion; } \\
\text { droplet size } \\
<250 \mathrm{~nm} \\
\text { No diges- } \\
\text { tion needed } \\
\text { for drug ab- } \\
\text { sorption }\end{array}$ & $\begin{array}{l}\text { Transparent } \\
\text { dispersion } \\
\text { No diges- } \\
\text { tion needed } \\
\text { for drug ab- } \\
\text { sorption }\end{array}$ & $\begin{array}{l}\text { Good sol- } \\
\text { vent capa- } \\
\text { city for } \\
\text { many drugs }\end{array}$ \\
\hline Disadvantages & $\begin{array}{l}\text { Poor solvent } \\
\text { capacity for } \\
\text { the drug } \\
\text { with inter- } \\
\text { mediate log } \\
\text { P values } \\
\text { Suitable on- } \\
\text { ly for lipo- } \\
\text { philic drugs } \\
\text { limited or } \\
\text { no disper- } \\
\text { sion } \\
\text { requires } \\
\text { digestion }\end{array}$ & $\begin{array}{l}\text { Coarser } \\
\text { emulsion } \\
\text { (droplet size: } \\
0.25-2 \mu \mathrm{m} \text { ) }\end{array}$ & $\begin{array}{l}\text { Likely to } \\
\text { lose solvent } \\
\text { capacity on } \\
\text { dispersion } \\
\text { Less easily } \\
\text { digested }\end{array}$ & $\begin{array}{l}\text { May cause } \\
\text { partial drug } \\
\text { precipitation } \\
\text { Less easily } \\
\text { digested }\end{array}$ & $\begin{array}{l}\text { Risk of drug } \\
\text { precipitation } \\
\text { upon dis- } \\
\text { persion } \\
\text { May not be } \\
\text { digestible }\end{array}$ \\
\hline
\end{tabular}

tion of lymphatic drug transport $(10,13)$. Strategies for increasing the absorption of hydrophobic drugs with LBDDS are presented in Table III.

It is widely accepted that the performance of LBDDS is governed by their fate in the GIT, where dilution with aqueous media and digestion of LBDDS take place. Due to composition diversity, formulations belonging to different classes according to LFCS behave differently in the GIT. Type III and IV formulations may, for example, lose their sol- 
K. Čerpnjak et al.: Lipid-based systems as a promising approach for enhancing the bioavailability of poorly water-soluble drugs, Acta Pharm. 63 (2013) 427-445.

Table III. Strategies of LBDDS for increasing bioavailability of incorporated drugs

\begin{tabular}{|c|c|}
\hline Strategy & Brief explanation \\
\hline $\begin{array}{l}\text { Extended retention } \\
\text { in the stomach }\end{array}$ & $\begin{array}{l}\text { Introduction of lipids into the GIT results in slower peristaltic action and } \\
\text { gastric emptying, and consequently increased the retention time of its } \\
\text { content and possibly the co-administered drug in the upper intestine, } \\
\text { where absorption occurs. This contributes to more efficient dissolution } \\
\text { in the upper intestine and positively influences drug absorption }(9,14) \text {. }\end{array}$ \\
\hline $\begin{array}{l}\text { Increased } \\
\text { solubilization }\end{array}$ & $\begin{array}{l}\text { The presence of lipids in the GIT stimulates increased excretion of bile } \\
\text { salts and endogenous bile lipids (including cholesterol and phospholipids), } \\
\text { which facilitates emulsification of the lipids present and drug solubiliza- } \\
\text { tion. This leads to the formation of intestinal mixed micelles of endoge- } \\
\text { nous origin and increased solubilization capacity of the GIT for the drug } \\
(9,14,16) \text {. }\end{array}$ \\
\hline $\begin{array}{l}\text { Changes in the } \\
\text { biochemical barrier }\end{array}$ & $\begin{array}{l}\text { Some lipids and surfactants can reduce the activity of intestinal secretion } \\
\text { vectors in the gastrointestinal wall (such as P-glycoprotein) and inhibit } \\
\text { metabolic activity in the enterocytes and lumen of the GIT (e.g., cytochro- } \\
\text { mes), which contributes to enhanced absorption of drugs that are sub- } \\
\text { strates for these enzymes or transporters }(9,14-16) \text {. }\end{array}$ \\
\hline $\begin{array}{l}\text { Changes in the } \\
\text { physical barrier }\end{array}$ & $\begin{array}{l}\text { Various combinations of lipids and/or surfactants and their digestion } \\
\text { products may act as promoters of intestinal absorption due to increased } \\
\text { membrane permeability. Surfactants can cause fluidization of the intestinal } \\
\text { cell membrane and opening of tight junctions, which results in increased } \\
\text { membrane permeability }(9,14,16) \text {. }\end{array}$ \\
\hline \multirow{2}{*}{$\begin{array}{l}\text { Stimulation of } \\
\text { intestinal lymphatic } \\
\text { transport }\end{array}$} & $\begin{array}{l}\text { Lipids composed of LCT or MCT are differently transported in the body; } \\
\text { whereas MCT is directly transported by the portal blood to systemic circu- } \\
\text { lation, LCT stimulates the formation of lipoproteins, which facilitates their } \\
\text { lymphatic transport. }\end{array}$ \\
\hline & $\begin{array}{l}\text { LBDDS containing LCT are therefore likely to enhance the lymphatic trans- } \\
\text { port of a lipophilic drug substance, and thus they can also affect the extent } \\
\text { of the first-pass metabolism as the intestinal lymph circulation bypasses } \\
\text { the liver }(9,14-16) \text {. }\end{array}$ \\
\hline
\end{tabular}

vent capacity on dispersion due to diffusion of water-soluble components into the bulk aqueous phase, leading to drug precipitation $(13,16,17)$. Digestion of some formulation components in the GIT can also contribute to decreased solvent capacity. Besides solubilization capacity and droplet size of dispersions formed, the self-emulsifying ability also depends on the functionality of excipients, which thus influences the drug absorption process. The formulation-related factors affecting the bioavailability of drugs that are delivered in LBDDS are presented in Table IV.

\section{Excipients for lipid-based formulations}

Common selection criteria. - When formulating LBDDS, drugs have to be incorporated into an appropriate mixture of oil(s) and surfactant(s); therefore formulation development commonly starts with excipient selection. As there are many lipid-based substances that can be used for formulating LBDDS, some general criteria for excipient 
K. Čerpnjak et al.: Lipid-based systems as a promising approach for enhancing the bioavailability of poorly water-soluble drugs, Acta Pharm. 63 (2013) 427-445.

Table IV. Formulation parameters affecting bioavailability of drugs from LBDDS

Factor Explanation

If the drug possesses high affinity to the lipid vehicle, it can be assumed that it moves through the GIT incorporated into lipid droplets indicating that the Lipid digestion digestibility of the lipid would be as important as its gastric emptying rate. Thus, careful selection of the lipid excipient can control the absorption rate of the drug (10).

This parameter indicates the type and, according to some researchers, also the quality of LBDDS. Droplet size of the dispersion formed upon dilution of SEDDS and SMEDDS with aqueous media is primarily influenced by the type and concentration of surfactant(s): the higher the surfactant concentration, the smaller is the emulsion droplet and faster drug release $(10,18)$. Spontaneous formation of emulsion advantageously presents the drug in a

Mean emulsion droplet size

Lipophilicity of the API

Chemism of lipids dissolved form, and the resultant small droplet size provides a large interfacial surface area. These characteristics result in faster drug release from the emulsion in a reproducible manner, which can be designed further to make the release characteristics independent of the gastrointestinal physiology and the fed/fasted state of the patient (19).

The emulsion droplets formed are positively or negatively charged. As the mucosal lining is charged negatively, positively charged emulsion droplets can penetrate deeper into the ileum and cationic emulsions and thus exhibit greater bioavailability than anionic emulsions $(20,21)$.

Highly hydrophobic drugs $(\log P>5)$ can be taken up into the lymphatic system by partitioning into chylomicrons and avoiding the first-pass metabolism $(10,20)$.

The nature of lipids is important, since digestible lipids may influence absorption in a manner differing from that of non-digestible lipids (10). Enhanced drug absorption was reported when using LCT (long chain triglycerides) compared to MCT (medium chain triglycerides) in SMEDDS (22, 23); however, this cannot be taken as a rule.

selection were introduced in order to save time and cut costs. During preliminary selection studies, a few excipients are identified as possibly appropriate for further research owing to their safety, drug solubility and stability in excipients, and some other characteristics presented in Fig. 1. Initial selection of promising excipients is then followed by construction of phase diagrams to identify suitable mixing ratios for homogeneous formulations, being just as crucial as sufficient solubilization capacity for the drug to be incorporated. Once candidate formulations are proposed, the drug-loaded systems are subjected to in vitro dispersion and digestion tests to predict the fate of the drug in the GIT.

Oil phase. - The oil phase used to prepare LBDDS can be formulated from various non-polar components. The formation, stability and properties of dispersions formed from LBDDS often depend on the bulk physicochemical characteristics of the oil phase, e.g., polarity, water-solubility, interfacial tension with the water phase, viscosity, density, phase behavior and chemical stability (24). From a practical point of view, the oil phase 
K. Čerpnjak et al.: Lipid-based systems as a promising approach for enhancing the bioavailability of poorly water-soluble drugs, Acta Pharm. 63 (2013) 427-445.

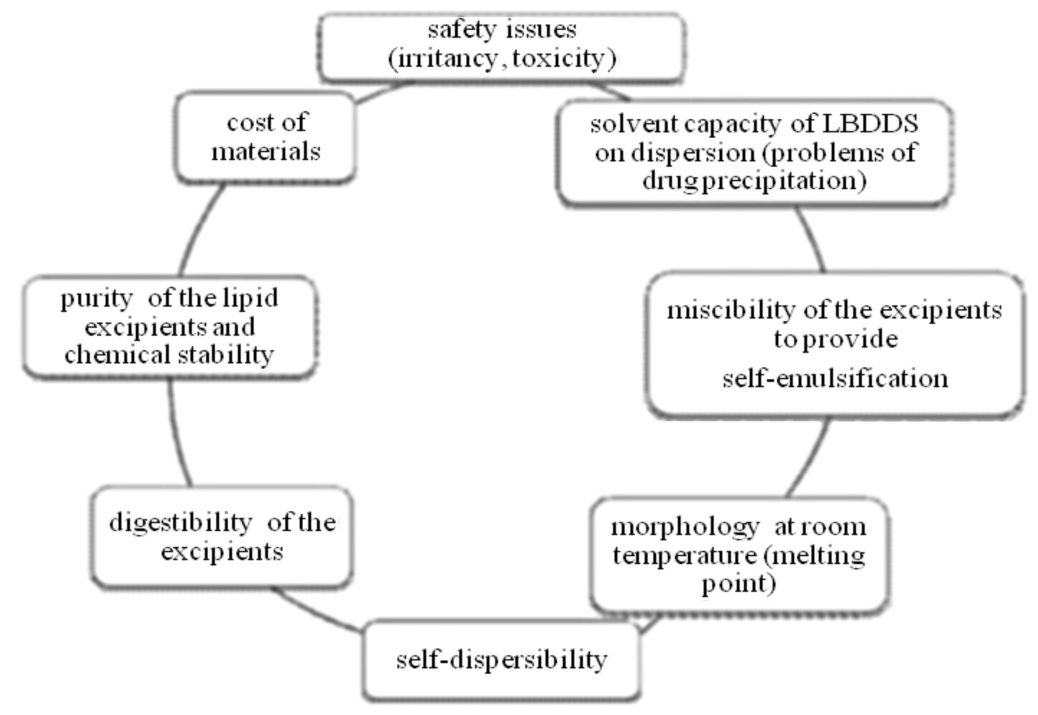

Fig. 1. General selection criteria for excipients in LBDDS (16).

highly influences dissolution of hydrophobic drugs and may contribute to their lymphatic transport. It also influences the self-emulsifying ability of the formulation and drug precipitation in the GIT.

The oil phase is usually composed of triglycerides or mixed glycerides (a mixture of mono-, di- and triglycerides) consisting of long-chain and/or medium-chain fatty acids. Some authors also report the use of hydrophobic surface-active agents named "polar oils « $(16,22,25-27)$. It is often desirable to prepare LBDDS using glycerides due to their safety status and low cost; therefore various types and properties of different mono-, diand triglycerides are presented in Table V. The majority of LBDDS described in the literature are composed of single lipid components. Lately, a growing interest in a more rational approach to excipient selection for lipid-based systems can be seen.

According to literature data, medium chain triglycerides (MCT) have been preferred for LBDDS due to their better solubilization properties, self-emulsification ability, and better chemical stability of active ingredients compared to long chain triglycerides (LCT). Grove et al. made a direct comparison of two seocalcitol II loaded SMEDDS containing either MCT or LCT. The study was performed on monophasic systems with the same lipid/surfactant/co-surfactant ratio, which formed dispersions with the same droplet size distribution upon dilution with the aqueous phase. Cremophor ${ }^{\circledR}$ RH40 was used as surfactant in both cases, whereas the co-surfactant was chosen to resemble the lipid component in chain length. Reportedly, a larger microemulsion area was achieved in the phase diagram when MCT was used instead of LCT due to the difference in polarity between the lipids. As the more hydrophobic LCT is more difficult to emulsify, higher concentration of Cremophor ${ }^{\circledR} \mathrm{RH} 40$ was generally required to form microemulsions when using LCT compared to MCT. Nevertheless, no significant differences were observed in the absorption and bioavailability of seocalcitol between the two aforemen- 
K. Čerpnjak et al.: Lipid-based systems as a promising approach for enhancing the bioavailability of poorly water-soluble drugs, Acta Pharm. 63 (2013) 427-445.

Table V. Classification of glycerides according to the number and length of fatty acids esterified with glycerol

\begin{tabular}{|c|c|c|}
\hline Class & Example & Characteristics \\
\hline \multirow{5}{*}{ 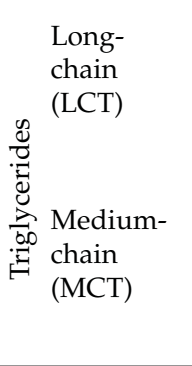 } & \multirow{5}{*}{$\begin{array}{l}\text { Corn oil, soybean oil, } \\
\text { olive oil, peanut oil, } \\
\text { sesame oil, sunflower } \\
\text { oil, castor oil, etc. } \\
\text { Fractionated coconut } \\
\text { oil, palm seed oil, } \\
\text { triglycerides of } \\
\text { caprylic/ capric acid } \\
\text { Miglyol }^{\circledR} 812, \\
\text { Captex }^{\circledR} 355\end{array}$} & \multirow{2}{*}{$\begin{array}{l}\text { GRAS status, easily ingested, digested, and absor- } \\
\text { bed, poor self-dispersing properties of LCT and ge- } \\
\text { nerally lower loading capacity for drugs with inter- } \\
\text { mediate log P values. Their advantage is generally a } \\
\text { higher solubilizing capacity after dispersion and di- } \\
\text { gestion of the formulation }(25,26,32) \text {. }\end{array}$} \\
\hline & & \\
\hline & & \multirow{3}{*}{$\begin{array}{l}\text { MCTs exhibit a good solubilizing capacity for less } \\
\text { lipophilic drugs and good self-dispersing ability. } \\
\text { Semisynthetic MCT with hydrogenated double } \\
\text { bonds are resistant to oxidation }(25,26,32) \text {. }\end{array}$} \\
\hline & & \\
\hline & & \\
\hline $\begin{array}{l}\text { Mixed mono-, } \\
\text { di- and tri- } \\
\text { glycerides }\end{array}$ & 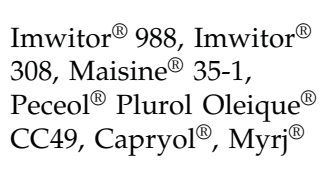 & $\begin{array}{l}\text { They possess surface active properties because of } \\
\text { their amphiphilic nature and are effective in replac- } \\
\text { ing conventionally used oils owing to their better } \\
\text { self-dispersing ability and higher solubilizing capa- } \\
\text { city for poorly water-soluble drugs }(25,26) \text {. }\end{array}$ \\
\hline
\end{tabular}

tioned SMEDDS upon their oral administration to male rats (28). This is contrary to previous studies, where the bioavailability of danazol and halofantrine from SMEDDS containing LCT was found to be superior to SMEDDS containing MCT $(22,29)$. However, SMEDDS compared in these studies consisted of different amounts of lipid and surfactant, whereas Grove et al. used quantitatively comparable systems. Considering the mentioned data, one can conclude that the extent of influence of MCT and LCT on the bioavailability of drugs is drug specific.

Besides the chain length of glycerides, solubility properties and self-emulsification ability of the formulation are further influenced by the type of glycerides used, since mono- and diglycerides possess amphiphilic properties whereas triglycerides do not. Hetal N. Prajapati et al. carried out a comparative evaluation of mixed glycerides of medium-chain fatty acids to develop a pharmaceutical dosage form with the model drug danazol. Phase diagrams were prepared using a monoglyceride (glycerol monocaprylocaprate: Capmul ${ }^{\circledR} \mathrm{MCM}$ ), a diglyceride (glycerol dicaprylate) and two triglycerides (glycerol tricaprylate: Captex ${ }^{\circledR} 8000$; caprylic/capric triglycerides: Captex ${ }^{\circledR} 355 \mathrm{EP} / \mathrm{NF}$ ) as the oil phase in combination with common surfactants (PEG-35 castor oil: Cremophor ${ }^{\circledR}$ EL) and water as the hydrophilic phase. They revealed that the use of the monoglyceride resulted in the formation of clear or translucent microemulsions, whereas the formation of an additional gel phase was observed when the oil phase consisted of di- and triglycerides. Among individual mono-, di- and triglycerides, the largest oil-in-water microemulsion region was that for the diglyceride. By adding the monoglyceride to di- or triglycerides (1:1), the region of this gel phase region formation could be practically eliminated. The oil phase composed of mixed glycerides further resulted in an expanded region of microemulsion formation in the phase diagram (30). 
K. Čerpnjak et al.: Lipid-based systems as a promising approach for enhancing the bioavailability of poorly water-soluble drugs, Acta Pharm. 63 (2013) 427-445.

Bolko et al. made a direct comparison between SMEDDS composed of the mixed lipid phase (containing castor oil as long-chain triglycerides, and Capmul ${ }^{\circledR} \mathrm{MCM}$ as medium-chain mono- and diglycerides) and the corresponding single lipid systems. They investigated whether the heterogeneous oil phase composed of medium- and long-chain mixed glycerides hasd a beneficial impact on SMEDDS self-emulsifying properties in comparison with a single lipid phase. According to their study, SMEDDS containing mixed glycerides showed the best self-emulsifying ability with regard to self-emulsifying time as well as droplet size and homogeneity of microemulsions obtained upon SMEDDS dilution with the aqueous phase (31).

Small (33) developed a physicochemical system to classify lipids (including surfactants) into non-polar and polar lipids based on their interaction with bulk water and their behavior at the water-air interface. This classification is presented in Table VI. Non-polar lipids do not spread to form a monolayer on water surface and are insoluble in bulk water (examples: alkanes, liquid paraffin, cholesterol esters, and fatty-acid esters, including waxes). Polar lipids are divided into four different classes and are described as insoluble non-swelling, insoluble swelling, and soluble. Soluble polar lipids are fur-

Table VI. Classification of polar lipids by Small (33)

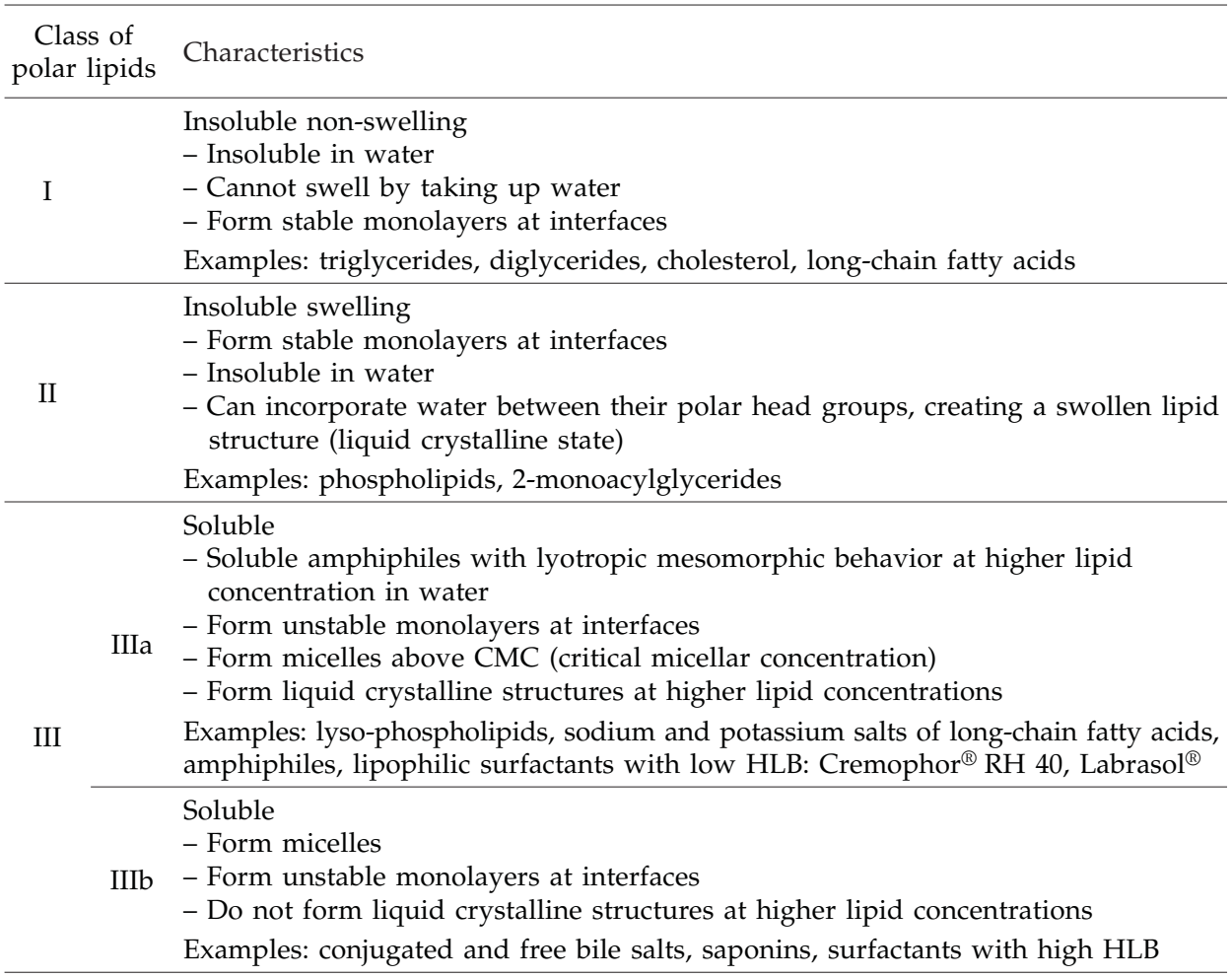


K. Čerpnjak et al.: Lipid-based systems as a promising approach for enhancing the bioavailability of poorly water-soluble drugs, Acta Pharm. 63 (2013) 427-445.

ther divided into two sub-classes depending on whether or not they show formation of liquid crystalline structures at higher lipid concentration in bulk (33).

While Small's classification is focused on lipid excipients, the LCFS introduced by Pouton emphasized the differences among various types of lipid formulations. In addition, Small's classification also includes highly hydrophilic surfactants with high HLB values (e.g., Cremophor ${ }^{\circledR}$ RH 40, which has a HLB value around 15). Nevertheless, surfactants cannot be compared to lipids and cannot replace them due to their physicochemical characteristics and irritation potential.

Therefore the aforementioned classifications cannot be used as alternatives but are supplementary since they can both contribute useful information to formulators.

Surfactants. - Selection of an appropriate emulsifier is one of the most important factors to consider for the proper design of LBDDS. The stability of dispersions formed from LBDDS to environmental stresses such as $\mathrm{pH}$, ionic strength, and temperature variation is often predominantly determined by the type of emulsifier used. It is generally acceptable that most stable emulsions are formed in the presence of surfactant combinations, in which one acts as an emulsifier and the other as a co-emulsifier, depending on their HLB values.

Table VII. Surfactants classified according to their $\operatorname{HLB}$ number $(36,37)$

\begin{tabular}{|c|c|}
\hline HLB value & Type of surfactant \\
\hline \multirow{4}{*}{$\begin{array}{l}\text { Low HLB } \\
(<10)\end{array}$} & $\begin{array}{l}\text { Phosphatidylcholine and phosphatidylcholine mixtures } \\
\text { Phosphatidylcholine, mixtures in propylene glycol / MCT, ethanol }\end{array}$ \\
\hline & $\begin{array}{l}\text { Unsaturated polyglycolized glycerides (macrogolglycerides) } \\
\text { Labrafil }^{\circledR} \text { M1944 CS, Labrafil }{ }^{\circledR} \text { M2125CS }\end{array}$ \\
\hline & $\begin{array}{l}\text { Sorbitan esters } \\
\text { Capmul }^{\circledR}, \text { Capmul }^{\circledR} \text { S, Span }{ }^{\circledR} 20, \text { Span }^{\circledR} 40\end{array}$ \\
\hline & $\begin{array}{l}\text { Polyethoxylated alkyl ethers } \\
\text { Brijs }^{\circledR} 30,52,72\end{array}$ \\
\hline \multirow{7}{*}{$\begin{array}{l}\text { High HLB } \\
(>10)\end{array}$} & $\begin{array}{l}\text { Polyoxyethylene sorbitan esters (polysorbates) } \\
\text { Tweens }^{\circledR} 20,40,60,80\end{array}$ \\
\hline & $\begin{array}{l}\text { Polyethoxylated fatty acid ester } \\
\text { Myrj }^{\circledR} 52, \text { Solutol }^{\circledR} \text { HS15 }\end{array}$ \\
\hline & $\begin{array}{l}\text { Polyethoxylated alkyl ethers } \\
\text { Brijs }{ }^{\circledR} 35,56,78\end{array}$ \\
\hline & $\begin{array}{l}\text { Polyethoxylated glycerides } \\
\text { Caprylo/caproil macrogolglyceride: Labrasol }{ }^{\circledR}\end{array}$ \\
\hline & $\begin{array}{l}\text { Polyoxyl castor oil derivatives } \\
\text { Polyoxyl } 35 \text { castor oil: Cremophor }{ }^{\circledR} \text { EL, } \\
\text { Polyoxyl } 40 \text { hydrogenated castor oil: Cremophor }{ }^{\circledR} \text { RH40 }\end{array}$ \\
\hline & $\begin{array}{l}\text { Polyoxyethylene polyoxypropylene block copolymer } \\
\text { Poloxamer }^{\circledR} 188 \text {, Poloxamer }{ }^{\circledR} 407\end{array}$ \\
\hline & $\begin{array}{l}\text { Saturated polyglycolized glycerides } \\
\text { Lauroyl macrogolglycerides: Gelucire }{ }^{\circledR} 44 / 14 \text {, } \\
\text { Stearoyl macrogolglycerides: Gelucire }{ }^{\circledR} 50 / 13\end{array}$ \\
\hline
\end{tabular}


K. Čerpnjak et al.: Lipid-based systems as a promising approach for enhancing the bioavailability of poorly water-soluble drugs, Acta Pharm. 63 (2013) 427-445

An emulsifier is a surface-active molecule that partitions at the oil-water interface and stabilizes the internal phase of emulsion delivery systems by lowering the interfacial tension and protecting droplets against aggregation. According to their HLB value, they are categorized as lipophilic (HLB $\leq 10)$ or hydrophilic (HLB $>10)$ surfactants, as presented in Table VII. Nonionic hydrophilic surfactants are generally required for SEDDS and SMEDDS formulation, with HLB values above 12 (Gelucire ${ }^{\circledR}$ 44/14, Gelucire $^{\circledR} 50 / 13$, Labrasol ${ }^{\circledR}$, Cremophor $^{\circledR}$ EL, Cremophor ${ }^{\circledR}$ RH 40, etc.) needed to obtain systems that spontaneously form oil-in-water dispersions with droplet size below $100 \mathrm{~nm}$ upon dilution with digestive fluids in GIT (34).

The choice of surfactants is limited since very few are acceptable for oral administration. Safety is a major determining factor when choosing a surfactant. In keeping with this, the nonionic surfactants, such as polyethoxylated lipid derivatives, are the most widely recommended and used ones $(16,35)$. These surfactants can consist of fatty acids, alcohols, or glycerides, which are linked to a certain number of repeating polyethylene oxide units through ester linkage (fatty acids and glycerides) and ether linkage (alcohols). Polyethylene groups provide hydrophilic characteristics (36, 37). In addition, emulsifiers of natural origin are preferred since they are considered to be safer than synthetic surfactants (27).

Besides the lower toxicity of nonionic surfactants compared to anionic and cationic ones, they also enable good stabilization of emulsions over a wider range of ionic strength and $\mathrm{pH}$. On the other hand, a possible disadvantage is their influence on the permeability of intestinal lumen with a reversible effect. Once again, this impact is generally less problematic than in the case of ionic surfactants. The surfactant concentration required to form a stable SMEDDS ranges from 30 to $60 \%(\mathrm{~m} / \mathrm{m})(34,38)$. The lowest possible surfactant concentration should be used in order to prevent gastric irritation. The extremely small droplet size produced in the case of SMEDDS promotes rapid gastric emptying and low local concentration of the surfactant, thereby reducing gastric irritation. Surfactant concentration has been shown to have varying effects on the droplet size of emulsion. Increase in surfactant concentration causes a decrease in droplet size associated with stabilization of surfactant molecules at the oil-water interface, although the reverse is possible due to enhanced water penetration into oil droplets leading to their breakdown (39-41).

Co-solvents. - Co-solvents in LBDDS are used in order to increase the solubilization capacity of incorporated drugs and to enhance dispersibility of hydrophilic surfactants in the oil phase, thus promoting formulation homogeneity and stability. In general, medium-chain-length alcohols (8 to $12 \mathrm{C}$ atoms) are adequate. Otherwise, derivatives of ethylene-glycol, glycerol, and propylene glycol can be also included $(11,16,34)$. When choosing between co-solvent and co-surfactant, one should consider lower solubilization capacity for hydrophobic drugs observed upon diluting co-solvent-containing formulations with the aqueous phase (28). This is related to the large amount of co-solvent usually needed to improve the drug solubilization capacity, which in turn increases the risk of drug precipitation when the formulation is dispersed in aqueous media. While in the presence of co-surfactants the co-administered drug is solubilized in micellar structures, systems containing co-solvents lose their solvent capacity faster due to solvent diffusion into aqueous media. 
K. Čerpnjak et al.: Lipid-based systems as a promising approach for enhancing the bioavailability of poorly water-soluble drugs, Acta Pharm. 63 (2013) 427-445.

Furthermore, use of a co-solvent increases the complexity of the LBDDS production process. LBDDS can interact with primary packaging (e.g., gelatin capsules), and therefore LBDDS without alcohols and other volatile solvents are preferred (38).

Influence of the drug on the selection of excipients. - Poor water-soluble drugs are a broad class of compounds differing considerably in their properties. Although there is an endless number of possible combinations for LBDDS, knowing the structure and physicochemical properties of the drug candidate may make it possible to narrow the search, and identify the most appropriate formulation for specific drugs. For example, if the drug is an amine, it may be soluble in oleic acid through formation of an ion pair, as exhibited by commercial formulations of ritonavir and ritonavir/lopinavir (37). Further, it is useful to acknowledge that poorly water-soluble drugs are hydrophobic but not necessarily lipophilic, and can therefore be poorly soluble in glycerides. Nevertheless, hydrophobic non-ionizable drugs (generally characterized by a $\log P_{\text {oct } / \text { wat }} \geq 3$ ) may be solubilized by LCT or MCT and/or by a combination of a lipid with a low HLB surfactant such as phosphatidylcholine/MCT or oleoyl macrogolglycerides. Less hydrophobic drugs ( $\left.\log P_{\text {oct } / \text { wat }} \leq 3\right)$ may be solubilized by monoglycerides or propylene glycol monoesters, or by combinations of these lipids with high HLB surfactants or hydrophilic co-solvents (37). In any case, a systematic approach is needed to select the optimal formulation, since there are still insufficient comparative literature data available, which would enable formulators to make the most appropriate choices.

\section{Types of lipid-based drug delivery systems}

There are various types of LBDDS; from simple drug in lipid solutions or suspensions, to emulsions and more complex self-emulsifying, self-microemulsifying, or self-nanoemulsifying (SEDDS/SMEDDS/SNEDDS) systems.

Type II and IIIa formulations according to LBCS are generally named SEDDS. They are formulated with mixtures of lipid vehicles, non-ionic surfactants and drug in the absence of water, and are assumed to exist as transparent isotropic solutions. These systems have a unique property: they are able to self-emulsify rapidly in the gastrointestinal fluids, forming fine oil-in-water emulsions (droplet size diameter $<300 \mathrm{~nm}$ ) under gentle agitation provided by gastrointestinal motion. SEDDS are commonly suitable for oral delivery in soft and hard gelatin or hard hydroxypropyl methylcellulose (HPMC) capsules $(14,39,40)$.

Type IIIb formulations according to LBCS are commonly called SMEDDS and are defined as isotropic mixtures of an oil, surfactant, co-surfactant (or solubilizer) and drug. Such systems form fine oil-in-water microemulsions under gentle agitation provided by digestive motility of the stomach and intestine following dilution by the aqueous phase in vivo. SMEDDS are distinguished from SEDDS by smaller emulsion droplets produced on dilution, resulting in a transparent or translucent stable dispersion. Mean droplet size after dilution is $<100 \mathrm{~nm}$ in the case of SMEDDS or $<300 \mathrm{~nm}$ in the case of SEDDS. SMEDDS generally contain relatively high concentrations of surfactant (typically 30 to $60 \%, \mathrm{~m} / \mathrm{m}$ ), and optionally also hydrophilic co-solvents (e.g., propylene gly$\mathrm{col}$, polyethylene glycols). They are often described as microemulsion pre-concentrates because the microemulsion is formed on dilution in aqueous media $(37,42-44)$. 
K. Čerpnjak et al.: Lipid-based systems as a promising approach for enhancing the bioavailability of poorly water-soluble drugs, Acta Pharm. 63 (2013) 427-445

It must be pointed out that it may not be appropriate to describe dispersions that are produced from SMEDDS routinely as microemulsions, although this terminology is widely used. Namely, according to the definition, microemulsions are thermodynamically stable systems that form spontaneously, whereas »microemulsions « formed upon diluting SMEDDS are not necessarily thermodynamically stable and may need some energy input (such as stirring or gastrointestinal motility) to be formed. Some authors therefore prefer to refer to the type IIIb formulations according to LBCS as self-nanoemulsifying drug delivery systems (SNEDDS) $(26,35,46,47)$. According to the scientific definition, this may be a more accurate terminology, as pointed out in a recent expert review by Anton and Vandamme (47). However, this also resulted in even bigger confusion regarding the terminology used, which is sometimes misleading. In concordance to type IIIb systems, SNEDDS spontaneously form transparent to opalescent oil-in-water dispersions of approximately $200 \mathrm{~nm}$ in size upon dilution with water under gentle stirring. The problem arises when some define SNEDDS as isotropic mixtures of oils, surfactants or, alternatively, one or more hydrophilic solvents and co-solvents/co-surfactants, and a drug, which are capable of forming thermodynamically stable oil-in-water nanoemulsions $(48,49)$. First, if SNEDDS consist of one or more hydrophilic solvents and co-solvents / co-surfactants, then such a formulation should be classified as type IV system according to LBCS, which is composed only of surfactants and co-solvents (no oil phase) and form a colloidal micellar dispersion upon dilution with aqueous phase. Even more problematic is defining nanoemulsions that are formed from SNEDDS in the presence of water as thermodynamically stable. Namely, nanoemulsions are thermodynamically unstable systems that will tend to break down over time. It is therefore important to note that the only emulsion-type system that is thermodynamically stable under particular environmental conditions (e.g., composition, pressure and temperature) is microemulsion (50). However, dispersion systems formed from type IIIb formulations are usually not thermodynamically stable and are more likely to be nanoemulsions than microemulsions. In keeping with this, it would be more accurate in most cases to name those systems SNEDDS instead of SMEDDS.

The characteristics differentiating SEDDS, SMEDDS and SNEDDS are presented in Table VIII; however, this terminology certainly needs clarification, as recently pointed out in an expert review by Anton and Vandamme, 2011.

In general, water-free systems (SEDDS, SMEDDS, SNEDDS) are preferred for oral preparation to the regular (micro-/nano-) emulsion system due to their lower volume and increased drug stability.

On the other hand, the advantage of microemulsions as potential therapeutic systems for oral delivery is their specific structure, which enables incorporation of hydrophilic, amphiphilic and lipophilic drugs to increase their solubility, rate and extent of absorption, to protect labile agents from the gastrointestinal environment, to reduce interand intrasubjective variability and to mask unpleasant odor and taste. Nevertheless, the therapeutic use of microemulsions as an oral dosage form is negligible. The main limiting factors are large volumes and composition requirements, namely, a high ratio of surfactants that are potentially toxic $(26,32,54,55)$. 
K. Čerpnjak et al.: Lipid-based systems as a promising approach for enhancing the bioavailability of poorly water-soluble drugs, Acta Pharm. 63 (2013) 427-445.

Table VIII. Characteristics of SEDDS, SMEDDS, and SNEDDS and dispersions obtained upon their dilution with the aqueous phase $(14,19,48,51)$

\begin{tabular}{|c|c|c|c|}
\hline $\begin{array}{l}\text { System/ } \\
\text { characteristic }\end{array}$ & SEDDS & SMEDDS & SNEDDS \\
\hline \multirow[t]{2}{*}{ Composition } & $\begin{array}{l}\text { Can be simple binary } \\
\text { formulations with the } \\
\text { drug and lipidic exci- } \\
\text { pient able to self-emul- } \\
\text { sify in contact with gas- } \\
\text { trointestinal fluids or a } \\
\text { system comprising a } \\
\text { drug, surfactant, and oil } \\
\text { (lipid phase) }\end{array}$ & $\begin{array}{l}\text { Composed of the drug } \\
\text { compound, surfactant, } \\
\text { co-surfactant, oil (lipid } \\
\text { phase) and optionally } \\
\text { hydrophilic co-solvent }\end{array}$ & $\begin{array}{l}\text { Composed of the drug } \\
\text { compound, oils, sur- } \\
\text { factant/co-surfactant } \\
\text { and hydrophilic sol- } \\
\text { vents }\end{array}$ \\
\hline & \multicolumn{3}{|c|}{$\begin{array}{l}\text { SEDDS, SMEDDS, and SNEDDS form a fine oil-in-water dispersion (emul- } \\
\text { sion, microemulsion, nanoemulsion) in contact with gastrointestinal fluids. }\end{array}$} \\
\hline $\begin{array}{l}\text { Lipid droplet } \\
\text { size in } \\
\text { dispersion }\end{array}$ & $\begin{array}{l}\text { From } 200 \mathrm{~nm} \text { to } 5 \mu \mathrm{m} \\
(14,48) \text { or more com- } \\
\text { monly } 100-300 \mathrm{~nm}(19), \\
\text { providing a large sur- } \\
\text { face area for absorption. } \\
\text { The dispersion has a } \\
\text { turbid appearance. }\end{array}$ & $\begin{array}{l}<50 \mathrm{~nm}(19) \text { or more } \\
\text { commonly }<100 \mathrm{~nm} \\
(52), \text { or }<140 \mathrm{~nm}(53) \\
\text { providing a large sur- } \\
\text { face area for absorption. } \\
\text { The dispersion has an } \\
\text { optically clear to trans- } \\
\text { lucent appearance. }\end{array}$ & $\begin{array}{l}<200 \mathrm{~nm}(14,48) \text { or } \\
\text { more commonly }<100 \\
\mathrm{~nm}(52) . \text { The dispersion } \\
\text { has an optically clear } \\
\text { appearance. }\end{array}$ \\
\hline $\begin{array}{l}\text { Solubilizing } \\
\text { capacity }\end{array}$ & \multicolumn{3}{|c|}{$\begin{array}{l}\text { SEDDS, SMEDDS, and SNEDDS have high solubilizing capacity and high } \\
\text { dispersibility. }\end{array}$} \\
\hline $\begin{array}{l}\text { Stability of } \\
\text { dispersions }\end{array}$ & $\begin{array}{l}\text { Thermodynamically } \\
\text { unstable }\end{array}$ & $\begin{array}{l}\text { Thermodynamically } \\
\text { stable }\end{array}$ & $\begin{array}{l}\text { Kinetically stable } \\
\text { formulations. }\end{array}$ \\
\hline \multirow[t]{2}{*}{$\begin{array}{l}\text { Formulation } \\
\text { technique }\end{array}$} & $\begin{array}{l}\text { Development/optimiza- } \\
\text { tion of SEDDS may re- } \\
\text { quire the development } \\
\text { of ternary phase dia- } \\
\text { grams. }\end{array}$ & $\begin{array}{l}\text { Pseudo-ternary phase } \\
\text { diagrams are required } \\
\text { to optimize SMEDDS, } \\
\text { whereas the order of } \\
\text { mixing preselected com- } \\
\text { ponents is not impor- } \\
\text { tant. }\end{array}$ & $\begin{array}{l}\text { Techniques for prepar- } \\
\text { ing SNEDDS are not } \\
\text { completely defined, but } \\
\text { the order of mixing pre- } \\
\text { selected combinations } \\
\text { of components is de- } \\
\text { fined. }\end{array}$ \\
\hline & \multicolumn{3}{|c|}{$\begin{array}{l}\text { SEDDS, SMEDDS, and SNEDDS formulations can be prepared as liquids and } \\
\text { semi-solids for capsule dosage forms and solid forms for tableting. }\end{array}$} \\
\hline
\end{tabular}

Nanoemulsions are transparent or translucent dispersions with the droplet size in the same length-scale as microemulsions (52). They possess a relatively high kinetic stability and cannot form spontaneously and consequently energy input is required.

As discussed earlier, microemulsions and nanoemulsions are different types of colloidal dispersions also from the physicochemical point of view. It is therefore important to distinguish between them because this affects the methods used to fabricate them, the strategies used to stabilize them and the approaches used to design their functional attributes $(43,47)$. An expanded comparison of nanoemulsions and microemulsions is presented in Table IX. 
K. Čerpnjak et al.: Lipid-based systems as a promising approach for enhancing the bioavailability of poorly water-soluble drugs, Acta Pharm. 63 (2013) 427-445.

Table IX. Comparison of the characteristics of nanoemulsions and microemulsions $(32,35,43,47,52,53,55-57)$

\begin{tabular}{|c|c|c|}
\hline $\begin{array}{l}\text { System/ } \\
\text { Characteristics }\end{array}$ & Nanoemulsions & Microemulsions \\
\hline Stability & $\begin{array}{l}\text { Thermodynamically unstable but } \\
\text { kinetically stable systems }\end{array}$ & Thermodynamically stable systems \\
\hline Composition & Water, oil, surfactants & $\begin{array}{l}\text { Water, oil, surfactants, co-solvent } \\
\text { if needed }\end{array}$ \\
\hline $\begin{array}{l}\text { Order of } \\
\text { mixing }\end{array}$ & $\begin{array}{l}\text { Surfactants should be first mixed } \\
\text { with the oily phase, followed by } \\
\text { titration of the obtained mixture } \\
\text { with the aqueous phase. }\end{array}$ & $\begin{array}{l}\text { The order of mixing the components } \\
\text { does not affect formation. }\end{array}$ \\
\hline Droplet size & $\begin{array}{l}50-200 \mathrm{~nm}(58,59) \\
50-500 \mathrm{~nm}(60,61) \\
\text { generally accepted } \\
<100(10-100) \mathrm{nm}(52)\end{array}$ & $\begin{array}{l}\text { Droplet size }<140 \mathrm{~nm}(53) \text { or more } \\
\text { commonly } 2-100 \mathrm{~nm}(52) .\end{array}$ \\
\hline $\begin{array}{l}\text { Formulation } \\
\text { technique }\end{array}$ & $\begin{array}{l}\text { High-energy methods of preparation } \\
\text { use specific devices (ultrasound ge- } \\
\text { nerators, high pressure homogeni- } \\
\text { zers) to supply enough energy to } \\
\text { increase the interfacial area }(35,57)\end{array}$ & $\begin{array}{l}\text { Spontaneous formation } \\
\text { They exhibit a large range of struc- } \\
\text { tures: bicontinuous, hexagonal, } \\
\text { spherical, liquid crystalline }\end{array}$ \\
\hline
\end{tabular}

To distinguish whether the system formed is a microemulsion or nanoemulsion, one should first test if the order of mixing compounds during formulation affects the droplet size. If there is no influence, the system is most probably a microemulsion. They further differ considerably in their behavior during dilution with the aqueous phase. While microemulsions are strongly affected and even break down by dilution, nanoemulsion droplets will remain stable with unchanged droplet size distribution. Furthermore, varying the temperature can strongly affect the structures and droplet size in the case of microemulsions whereas it has no immediate effect on the structure of nanoemulsions; nevertheless, an effect is evident after some time because the temperature has influence on the structure of surfactants.

An increase in temperature causes a decrease in the critical micelle concentration (CMC; concentration above which micelles are formed in solutions) due to destruction of hydrogen bonds between water molecules and hydrophilic groups of surfactants (62). The presented approaches can be also useful in distinguishing between SMEDDS and SNEDDS by testing dispersions formed upon their dilution with the aqueous phase.

\section{CONCLUSIONS}

Low water solubility is widely recognized as the main reason for the poor oral absorption of many drugs. Conventional solubilization approaches which include the use of surfactants, cyclodextrin complexes, salt formations, nanoparticles, solid dispersions, 
K. Čerpnjak et al.: Lipid-based systems as a promising approach for enhancing the bioavailability of poorly water-soluble drugs, Acta Pharm. 63 (2013) 427-445.

lipids, and permeation enhancers are employed in enhancing the oral absorption of drugs. However, one of the most promising novel approaches for enhancing solubility are undoubtedly LBDDS. They can be made as solutions, emulsions, suspensions, microemulsions, solid lipid nanoparticles, liposomes, SEDDS, SMEDDS, SNEDDS, dry emulsions, dry microemulsions, melted microemulsions, and solid dosage forms containing a LBDDS.

LBDDS are a successful strategy for increasing solubility and improving the bioavailability of poorly soluble drugs (BCS Classes II and IV). They attain increased absorption of poorly soluble drugs with specific mechanisms: extended time of retention in the stomach, an increase in solubilization, stimulation of gastrointestinal lymphatic transport and impact on the biochemical and physical barrier of the GIT. Their effectiveness, however, also depends on the composition and proportion of the components. Different aspect ratios and different types of excipients determine a particular delivery system. It is necessary to determine experimentally the appropriate composition of the selected delivery system for each individual drug and thus ensure maximum effectiveness of the selected LBDDS.

This review article will direct researchers' attention to understanding the role of individual components used for formulating LBDDS and to the critical distinction between SMEDDS and SNEDDS. It also offers inspiration and courage to introduce more LBDDS at pilot and industrial scales.

\section{REFERENCES}

1. J. M. Custodio, C. Y. Wu and L. Z. Benet, Predicting drug disposition, absorption/elimination/ transporter interplay and the role of food on drug absorption, Adv. Drug Deliver. Rev. 60 (2008) 717-733; DOI: 10.1016/j.addr.2007.08.043.

2. A. Chaudhary, U. Nagaich, N. Gulati, V. K. Sharma and R. L. Khosa, Enhancement of solubilization and bioavailability of poorly soluble drugs by physical and chemical modifications: A recent review, J. Adv. Pharm. Educ. Res. 2 (2012) 32-67.

3. K. Kohli, S. Chopra, D. Dhar, S. Arora and R. K. Khar, Self-emulsifying drug delivery systems: an approach to enhance oral bioavailability, Drug Discov. Today 15 (2010) 958-965; DOI: 10.1016/ j.drudis.2010.08.007.

4. Y. Kawabata, K. Wada, M. Nakatani, S. Yamada and S. Onoue, Formulation design for poorly water-soluble drugs based on biopharmaceutics classification system: Basic approaches and practical applications, Int. J. Pharm. 420 (2011) 1-10; DOI: 10.1016/j.ijpharm.2011.08.032.

5. T. Loftsson, E. M. Brewater and M. Masson, Role of cyclodextrins in improving oral drug delivery, Am. J. Drug Deliv. 2 (2004) 261-275; DOI: 10.2165/00137696-200402040-00006.

6. S. B. Murdandea and M. J. Gumkowskia, Development of a self-emulsifying formulation that reduces the food effect for torcetrapib: An overview, Int. J. Pharm. 51 (2008) 15-22; DOI: 10. 1016/j.ijpharm.2007.09.015.

7. J. Parul, A. Geeta and K. Amanpreet, Bioavailability enhancement of poorly soluble drugs by SMEDDS: A review, J. Drug Deliv. Ther. 3 (2013) 98-109.

8. S. Saroy, D. A. Baby and M. Sabitha, Current trends in lipid based delivery systems and its applications in drug delivery, Asian J. Pharm. Clin. Res. 5 (2012) 4-9.

9. H. J. C. Porter, L. N. Trevaskis and W. N. Charman, Lipids and lipid-based formulations: optimizing the oral delivery of lipophilic drugs, Nat. Rev. Drug Discov. 6 (2007) 231-248; DOI: 10. $1038 /$ nrd2197. 
K. Čerpnjak et al.: Lipid-based systems as a promising approach for enhancing the bioavailability of poorly water-soluble drugs, Acta Pharm. 63 (2013) 427-445.

10. B. K. Nanjwade, D. J. Patel, R. A. Udhani and F. V. Manvi, Function of lipids for enhancement of oral bioavailability of poorly water-soluble drugs, Sci. Pharm. 79 (2011) 705-727; DOI: 10.3797/ scipharm.1105-09.

11. W. C. Pouton and J. H. C. Porter, Formulation of lipid-based delivery systems for oral administration: Materials, methods and strategies, Adv. Drug Deliver. Rev. 60 (2008) 625-637; DOI: 10. 1016/j.addr.2007.10.010.

12. W. C. Pouton, Formulation of poorly water-soluble drugs for oral administration: Physicochemical and physiological issues and the lipid formulation classification system, Eur. J. Pharm. Sci. 29 (2006) 278-287; DOI: 10.1016/j.ejps.2006.04.016.

13. V. Jannin, J. Musakhanian and D. Marchaud, Approaches for the development of solid and semi-solid lipid-based formulations, Adv. Drug Deliver. Rev. 60 (2008) 734-746; DOI: 10.1016/j. addr.2007.09.006.

14. B. V. Rajesh, T. K. Reddy, G. Srikanth, V. Mallikarjun and P. Nivethithai, Lipid based self-emulsifying drug delivery system (SEDDS) for poorly water-soluble drugs: A review, J. Glob. Pharma Technol. 2 (2010) 47-55.

15. R. N. Gupta, R. Gupta and R. G. Singh, Enhancement of oral bioavailability of lipophilic drugs from self-microemulsifying drug delivery systems (SMEDDS), Int. J. Drug Dev. Res. 1 (2009) 1018.

16. K. Mohsin, A. A. Shahba and F. K. Alanazi, Lipid based self-emulsifying formulations for poorly water soluble drugs- an excellent opportunity, Ind. J. Pharm. Edu. Res. 46 (2012) 88-96.

17. P. Gao and W. Morozowich, Development of supersaturatable self-emulsifying drug delivery system formulation for improving the oral absorption of poorly soluble drugs, Expert Opin. Drug Del. 3 (2006) 97-110; DOI: 10.1517/17425247.3.1.97.

18. B. D. Tarr and S. H. Yalkowsky, Enhanced intestinal absorption of cyclosporine in rats through the reduction of emulsion droplet size, Pharm. Res. 6 (1989), 40-43; DOI: 10.1023/A:10158435 17762.

19. B. Singh, S. Bandopadhyay, R. Kapil, R. Singh and O. Katare, Self-emulsifying drug delivery systems (SEDDS): Formulation development, characterization, and applications, Crit. Rev. Ther. Drug 26 (2009) 427-521.

20. J. H. Lin, W. Chen and J. King, The effect of dosage form on oral absorption of L-365, 260, a potent CCK receptor antagonist in dogs, Pharm. Res. 8 (1991) 272.

21. M. J. Groves and D. A. Degalindez, The self-emulsifying action of mixed surfactants in oil, Acta Pharm. Suec. 13 (1976) 361-372.

22. S. M. Khoo, A. J. Humberstone, C. J. H. Porter, G. A. Edwards and W. N. Charman, Formulation design and bioavailability assessment of lipidic self-emulsifying formulations of halofantrine, Int. J. Pharm. 167 (1998) 155-164; DOI: 10.1016/S0378-5173(98)00054-4.

23. K. J. Palin and C. G. Wilson, The effect of different oils on the absorption of probucol in the rat, J. Pharm. Pharmacol. 36 (1984) 641-643; DOI: 10.1111/j.2042-7158.1984.tb04919.

24. J. Rao and D. J. McClements, Formation of flavor oil microemulsions, nanoemulsions and emulsions: influence of composition and preparation method, J. Agric. Food Chem. 59 (2011) 50265035; DOI: 10.1021/jf200094m.

25. M. Stuchlik and S. Žák, Lipid-based vehicle for oral drug delivery, Biomed. Pap. 145 (2001) 1726.

26. P. Constantinides, Lipid microemulsions for improving drug dissolution and oral absorption: physical and biopharmaceutical aspects, Pharm. Res. 12 (1995) 1561-1572; DOI: 10.1023/A: 1016268311867.

27. M. Kimura, M. Shizuki, K. Miyoshi, T. Sakai, H. Hidaka, H. Takamura and T. Matoba, Relationship between the molecular structures and emulsification properties of edible oils, Biosci. Biotech. Bioch. 58 (1994) 1258-1261; DOI: 10.1271/bbb.58.1258. 
K. Čerpnjak et al.: Lipid-based systems as a promising approach for enhancing the bioavailability of poorly water-soluble drugs, Acta Pharm. 63 (2013) 427-445.

28. M. Grovea and A. Mullertzb, Bioavailability of seocalcitol II: development and characterisation of self-microemulsifying drug delivery systems (SMEDDS) for oral administration containing medium and long chain triglycerides, Eur. J. Pharm. Sci. 28 (2006) 233-234; DOI: 10.1016/j.ejps. 2006.02.005.

29. C. J. Porter, A. M. Kaukonen and B. J. Boyd, Susceptibility to lipase-mediated digestion reduces the oral bioavailability of danazol after administration as a medium-chain lipid-based microemulsion formulation, Pharm. Res. 8 (2004) 1405-1412; DOI: 10.1023/B:PHAM.0000036914. 22132.cc.

30. H. N. Prajapati, M. D. Dalrymple and T. M. A. Serajuddin, A comparative evaluation of mono-, di- and triglyceride of medium chain fatty acids by lipid/surfactant/water phase diagram, solubility determination and dispersion testing for application in pharmaceutical dosage form development, Pharm. Res. 29 (2012) 285-305; DOI: 10.1007/s11095-011-0541-3.

31. K. Bolko, A. Zvonar and M. Gašperlin, Mixed lipid phase SMEDDS as an innovative approach to enhance resveratrol solubility, Drug Dev. Ind. Pharm. 2013, in press; DOI: 10.3109/03639045. 2012.749888.

32. P. P. Constantinides and J. P. Scalart, Formulation and physical characterization of water-in-oil microemulsions containing long- versus medium-chain glycerides, Int. J. Pharm. 158 (1997) 5768; DOI: 10.1016/S0378-5173(97)00248-2.

33. D. M. Small, Surface and bulk interactions of lipids and water with a classification of biologically active lipids based on these interactions, Fed. Proc. 29 (1970) 1320-1326.

34. W. C. Pouton, Properties and uses of common formulation lipids, surfactants and cosolvents, in AAPS, Workshop, March 2007.

35. N. H. Shah, M. T. Carvajal, C. I. Patel, M. H. Infeld and A. W. Malick, Self-emulsifying drug delivery systems (SEDDS) with polyglycolized glycerides for improving in vitro dissolution and oral absorption of lipophilic drugs, Int. J. Pharm. 106 (1994) 15-23.

36. Pharmaceutical Excipients, Product Reference Quick Guide, Gattefosse, Version VIII, April 2012; http://www.drug-dev.com/Media/MarketPlaceMedia/2012\%20GUSA\%20PHARMA\%20EXCIPIENT \%20GUIDE\%204.16.12.pdf; access date December 12, 2012.

37. J. B. Cannon, Strategies to formulate lipid-based drug delivery systems, Am. Pharm. Rev. 14 (2011) 4 .

38. A. Zvonar, M. Gašperlin and J. Kristl, Samo(mikro)emulgirajoči sistemi - alternativen pristop za izbolšanje biološke uporabnosti lipofilnih učinkovin = Self(micro)emulsifying systems - alternative approach for improving bioavailability of lipophilic drugs, Farm. Vestn. 59 (2008), 263-268.

39. S. Charman, Self-emulsifying drug delivery systems: formulation and biopharmaceutic evaluation of an investigational lipophilic compound, Pharm. Res. 9 (1992) 87-93; DOI: 10.1023/A: 1018987928936.

40. R. Neslihan Gursoy and S. Benita, Self-emulsifying drug delivery systems (SEDDS) for improved oral delivery of lipophilic drugs, Biomed. Pharmacother. 58 (2004) 173-182; DOI: 10.1016/j. biopha.2004.02.001.

41. E. S. Swenson, W. B. Milisen and W. Curatolo, Intestinal permeability enhancement: efficacy, acute local toxicity and reversibility, J. Pharm. Res. 11 (1994) 1132-1142; DOI: 10.1023/ A:1018984 731584.

42. T. G. Mason, J. N. Wilking, K. Meleson, C. B. Chang and S. M. Graves, Nanoemulsions: formation, structure and physical properties, J. Phys-Condens. Mat. 18 (2006) 635-666; DOI: 10.1088/ 0953-8984/18/41/R01.

43. H. D. Oh, H. J. Kang, W. D. Kim, J. B. Lee, O. J. Kim, S. C. Yong and G. H. Choi, Comparison of solid self-microemulsifying drug delivery system (solid SMEDDS) prepared with hydrophilic and hydrophobic solid carrier, Int. J. Pharm. 420 (2011) 412-418; DOI: 10.1016/j.ijpharm.2011. 09.007. 
K. Čerpnjak et al.: Lipid-based systems as a promising approach for enhancing the bioavailability of poorly water-soluble drugs, Acta Pharm. 63 (2013) 427-445.

44. K. B. Kang, J. S. Lee and S. K. Chon, Development of self-microemulsifying drug delivery systems (SMEDDS) for oral bioavailability enhancement of simvastatin in beagle dogs, Int. J. Pharm. 274 (2004) 65-73; DOI: 10.1016/j.ijpharm.2003.12.028.

45. S. Nazzal, I. SmalyukhI, O. D. Lavrentovich and M. A. Khan, Preparation and in vitro characterization of a eutectic based semisolid self-nanoemulsified drug delivery system (SNEDDS) of ubiquinone: mechanism and progress of emulsion formation, Int. J. Pharm. 235 (2002) 247-65; DOI: 10.1016/S0378-5173(02)00003-0.

46. C. W. Pouton, Lipid formulations for oral administration of drugs: non-emulsifying, self-emulsifying and self-microemulsifying drug delivery systems, Eur. J. Pharm. Sci. 11 (2000) 93-98; DOI: 10.1016/S0928-0987(00)00167-6.

47. N. Anton and T. F. Vandamme, Nano-emulsions and micro-emulsions: Clarifications of the critical differences, Pharm. Res. 28 (2011) 978-985; DOI: 10.1007/s11095-010-0309-1.

48. P. K. Suresh and S. Sharma, Formulation and in vitro characterization of self-nanoemulsifying drug delivery system of cinnarizine, Int. J. Compr. Pharm. 2011. ISSN 0976-8157.

49. D. Ghai and V. R. Sinha, Nanoemulsions as self-emulsified drug delivery carriers for enhanced permeability of the poorly water-soluble selective $\beta 1$-adrenoreceptor blocker Talinolol, Nanomed.-Nanotechnol. 8 (2012) 618-626; DOI: 10.1016/j.nano.2011.08.015.

50. S. Tenjarla, Microemulsions: an overview and pharmaceutical applications, Crit. Rev. Ther. Drug. 16 (1999) 461-521.

51. P. V. Chavda, Are SMEDDs and SNEDDs same? A gimmick or pharmaceutically relevant, Mintage J. Pharm. Med. Sci. 1 (2012) 7-10.

52. D. J. McClements and J. Rao, Food-grade nanoemulsions: Formulation, fabrication, properties, performance, biological fate and potential toxicity, Crit. Rev. Food Sci. 51 (2011) 285-330; DOI: 10.1080/10408398.2011.559558.

53. A. Martin, Physical Pharmacy, $4^{\text {th }}$ ed., Lea\&Febriger, London 1993, pp.127-128.

54. H. Araya, M. Tomita and M. Hayashi, The novel formulation design of O/W microemulsion for improving the gastrointestinal absorption of poorly water soluble compounds, Int. J. Pharm. 305 (2005) 61-74; DOI: 10.1016/j.ijpharm.2002.08.022.

55. J. M. Lawrence, Microemulsions as drug delivery vehicles, Colloid Interface Sci. 1 (1996) 826-832; DOI: 10.1016/S1359-0294(96)80087-2.

56. P. Solans, J. Nolla and N. Azemar, Nanoemulsions, Curr. Opin. Colloid In. 10 (2005) 102-110; DOI: 10.1016/j.cocis.2005.06.004.

57. M. Antonietti and K. Landfester, Polyreactions in miniemulsions, Prog. Polym. Sci. 27 (2002) 689-757; DOI: 10.1016/S0079-6700(01)00051-X.

58. T. Tadros, P. Izquierdo, J. Esquena and C. Solans, Formation and stability of nanoemulsions, Colloid Interface Sci. 108 (2004) 303-318; DOI: 10.1016/j.cis.2003.10.023.

59. V. Sadtler, M. Rondon-Gonzales, A. Acrement, A. Choplin and E. Marie, PEO-covered nanoparticles by emulsion. Inversion point (EIP) method, Macromol. Rapid Comm. 31 (2010) 998-1002; DOI: 10.1002/marc.200900835.

60. I. Sole, A. Maestro, C. Gonzales, C. Solans and J. M. Gutierrez, Optimization of nano-emulsion preparation by low-energy methods in an ionic surfactant system, Langmuir 22 (2006) 83268332; DOI: 10.1021/Ia0613676.

61. P. Shah, D. Bhalodia and P. Shelat, Nanoemulsion: A pharmaceutical review, Syst. Rev. Pharm. 1 (2010) 24-32; DOI: 10.4103/0975-8453.59509.

62. E. Mohajeri and G. D. Noudeh, Effect of temperature on the critical micelle concentration and micellization thermodynamic of nonionic surfactants: polyoxyethylene sorbitan fatty acid esters, E. J. Chem. 9 (2012) 2268-2274; DOI: 10.1155/2012/961739. 